\title{
Nummerierungen, Abkürzungen, Kennzeichnungen
}

Buchstaben als Grapheme (im Gegensatz zu einem Buchstaben in einer konkreten Inschrift) werden in spitze Klammern gesetzt, wie z. B.: Der Buchstabe $\langle B\rangle$ wird in der Kursivschrift deutlich anders gestaltet als in der Monumentalschrift.

Oskische Texte werden in der Regel nach Vetter 1953 in der Form „Ve 00“ angegeben. Falls sie dort noch nicht veröffentlicht wurden, folgt die Benennung der jüngeren Sammlung in Rix 2002, wo Texte aus Pompeji in der Form „Po 00“ und Texte aus der restlichen Campania mit „Cm 00“ aufgelistet sind.

Gräber in der Nekropole vor der Porta Ercolano werden entsprechend Kockel 1983 nummeriert, für die Nekropole vor der Porta Nocera folgt die Nummerierung der Einteilung bei D’Ambrosio/De Caro 1983.

Bei Graffitizeichnungen wird, sofern möglich, die Katalognummer aus Langner 2001 in der Form „Langner 0000“ angegeben.

Die Abkürzungen der Namen und Werktitel antiker Autoren richten sich nach DNP I (1996), XXXIX-XLVII.

Plin. nat. wird zitiert nach: C. Plini Secundi Naturalis historiae libri XXXVII recognovit et scripturae discrepantia adiecta edidit Carolus Mayhoff (Stuttgart 1967). Vitr. wird zitiert nach: Vitruvii de architectura libri decem edidit et adnotavit Dr. Curt Fensterbusch (Darmstadt 1964). Bei allen anderen zitierten Textstellen wird die verwendete Edition am Ort des Zitates angegeben.

Bei der Angabe der Himmelsrichtungen in Herculaneum wird die konventionelle Ausrichtung des Nordens auf den Vesuv beibehalten, da insbesondere die Fundorte der Inschriften mit Bezug auf diese Einordnung angegeben werden.

Die Farbabbildungen finden sich am Ende des Buches unter den Nummern F1-F69.

Ә Open Access. ( 2021 Fanny Opdenhoff, publiziert von De Gruyter. (c) BY-NC-ND Dieses Werk ist lizenziert unter der Creative Commons Attribution-NonCommercial-NoDerivatives 4.0 Lizenz. 
